\title{
Long-Term Effects of COVID-19 on Health Care Workers 1-Year Post-Discharge in Wuhan
}

\author{
Tingting Liao $\cdot$ Daquan Meng $\cdot$ Lijuan Xiong $\cdot$ Shuting $\mathrm{Wu} \cdot$ \\ Lian Yang $\cdot$ Sufei Wang $\cdot$ Mei Zhou Xinliang He $\cdot$ Xiongjing Cao · \\ Huangguo Xiong $\cdot$ Yunzhou Fan $\cdot$ Jiahong Xia $\cdot$ Yu Hu • \\ Yang Jin
}

Received: September 13, 2021 / Accepted: October 14, 2021 / Published online: October 23, 2021

(C) The Author(s) 2021

\section{ABSTRACT}

Introduction: To assess the long-term consequences of coronavirus disease (COVID-19) among health care workers (HCWs) in China (hereafter surviving HCWs).

Methods: A total of 303 surviving HCWs were included. Lung (pulmonary function test, 6-min walk test [6MWT], chest CT), physical (St.

Tingting Liao, Daquan Meng, Lijuan Xiong, and Shuting $\mathrm{Wu}$ have contributed equally to this work.

Supplementary Information The online version contains supplementary material available at https:// doi.org/10.1007/s40121-021-00553-0.

T. Liao - D. Meng - S. Wang - M. Zhou - X. He . Y. Jin $(\bowtie)$

Department of Respiratory and Critical Care Medicine, NHC Key Laboratory of Pulmonary Diseases, Tongji Medical College, Union Hospital, Huazhong University of Science and Technology, 1277 Jiefang Avenue, Wuhan 430022, Hubei, China e-mail: whuhjy@hust.edu.cn; whuhjy@126.com

L. Xiong $\cdot$ X. Cao $\cdot$ H. Xiong $\cdot$ Y. Fan

Department of Nosocomial Infection Management, Tongji Medical College, Union Hospital, Huazhong University of Science and Technology, 1277 Jiefang Avenue, Wuhan 430022, Hubei, China

$\mathrm{S}$. $\mathrm{Wu}$

Hubei Province Key Laboratory of Molecular Imaging, Wuhan 430022, China
George's Respiratory Questionnaire [SGRQ], Modified Medical Research Council dyspnea scale [mMRC], and Borg scale), and psychiatric functions (Essen Trauma Inventory) were evaluated during the 1-year follow-up.

Results: Surviving HCWs had an abnormal diffusion capacity 1 year post-discharge. Participants with a reduced carbon monoxide diffusing capacity (DLCO) comprised $43.48 \%$. The proportion of HCWs with a median 6MWT distance below the lower limit of the normal was $19.4 \%$. An abnormal CT pattern was observed in $37.5 \%$ of the HCWs. The SGRQ, mMRC, and Borg scores of surviving HCWs, especially those with critical/severe disease, were significantly higher than those in the

\footnotetext{
L. Yang

Department of Radiology, Tongji Medical College, Union Hospital, Huazhong University of Science and Technology, 1277 Jiefang Avenue, Wuhan 430022, Hubei, China

J. Xia $(\bowtie)$

Department of Cardiovascular Surgery, Tongji Medical College, Union Hospital, Huazhong University of Science and Technology, 1277 Jiefang Avenue, Wuhan, Hubei, China e-mail: jiahong.xia@hust.edu.cn

Y. $\mathrm{Hu}(\bowtie)$

Institute of Hematology, Tongji Medical College, Union Hospital, Huazhong University of Science and Technology, 1277 Jiefang Avenue, Wuhan 430022, Hubei, China

e-mail: dr_huyu@126.com
} 
normal population. Probable post-traumatic stress disorder (PTSD) was reported in $21.9 \%$ of the surviving HCWs. Diffusion capacity impairment was associated with women. Critical/severe illness and nurses were associated with impaired physical function.

Conclusions: Most surviving HCWs, especially female HCWs, still had an abnormal diffusion capacity at 1 year. The physical and psychiatric functions of surviving HCWs were significantly worse than those of the healthy population. Longterm follow-up of pulmonary, physical, and psychiatric functions for surviving HCWs is required.

Keywords: Long-term; COVID-19; SARS-CoV2; Lung function; Psychiatric function; Physical function

\section{Key Summary Points}

\section{Why carry out this study?}

HCWs have contributed greatly to the fight against coronavirus disease (COVID19), and the rehabilitation management of HCWs should be considered important. However, the information on long-term consequences and rehabilitation management of HCWs recovering from COVID-19 is limited

We aimed to evaluate the long-term pulmonary, physical, and mental health rehabilitation state of HCWs and their risk factors and correlation

\section{What were the study outcomes/ conclusions?}

Most surviving HCWs, especially females, had an abnormal diffusion capacity at 1 year

Long-term follow-up of pulmonary, physical, and psychiatric functions for surviving HCWs is required, and a comparison study of the difference in these long-term consequences between HCWs and non-HCWs is needed

\section{INTRODUCTION}

The outbreak of the coronavirus disease (COVID-19) in Wuhan, China, at the end of December 2019 has led to huge losses and caused considerable pressure on health care systems [1]. The new coronavirus, severe acute respiratory coronavirus 2 (SARS-CoV-2), is a highly contagious respiratory virus, and the population is generally susceptible.

Health care workers (HCWs) are essential workers in the management of patients with COVID-19; this includes daily epidemiological and clinical management/treatment. During the early phase of the outbreak, especially HCWS faced several challenges, such as lack of protective equipment (masks and protection suits), increased workload, extreme emotions, isolation, and loss of social support [2]. Existing literature suggests that the occupational risk of SARS-CoV-2 acquisition and development of psychological symptoms or mental disorders among front-line HCWs may be higher than that of the overall population $[3,4]$. In an early study of an epidemic outbreak, among 7736 patients diagnosed with COVID-19 in 552 hospitals as of 29 January 2020 in 31 Chinese provinces, health care staff comprised $3.5 \%$ [5]. In the USA, $11 \% \quad(1689 / 15,194$ patients) of all reported COVID-19 cases were identified as HCWs [6]. Italy also reported a high COVID-19 incidence among HCWs; HCWs accounted for $10 \%$ of all confirmed cases as of 5 April 2020, and 80 doctors and 25 nurses died from COVID-19 [7]. The COVID-19 incidence among HCWs from a review of 15 studies on SARS-CoV-2 was reported to be $1.9-29.4 \%$ [8]. The increased risk of SARS-CoV-2 infection may increase the risk of COVID-19-associated complications among HCWS.

Previous studies have suggested that despite long-term recovery, some COVID-19 survivors have sequelae, such as lung fibrosis, debilitating chronic symptoms, and/or psychological problems, which impact their quality of life [9-11]. HCWs have contributed greatly to the fight against COVID-19, and the rehabilitation management of HCWs should be considered important. The current epidemiology, clinical 
diagnosis, and treatment of COVID-19 have helped in gathering some experience, which has been used in conducting scientific studies. Some of such studies have suggested that some COVID-19 survivors present with health issues after discharge [12]. However, the information on long-term consequences and rehabilitation management of HCWs recovering from COVID19 is limited. Compared with non-HCWs, HCWs may have worse clinical outcomes because they are exposed to environments with a high SARS-CoV-2 density, have increased workload, and are more vulnerable to psychological trauma [13]. In addition, compared to non-HCWs, HCWs may be healthier, younger, or both. The high exposure of HCWs to COVID19 and the daily direct encounters with patients and COVID-19-related deaths may place frontline HCWs at a particularly high risk for pulmonary fibrosis and psychiatric disorders. A recent study reported no clear difference in COVID-19-related outcomes between HCWs and matched non-HCW controls [14]. However, the sample size of that study was small. Furthermore, studies have reported that $52 \%$ of COVID-19 survivors still had fatigue or muscle weakness at 6 months after discharge[15], and HCWs had a higher prevalence of anxiety, depression, insomnia, somatization, and obsessive-compulsive symptoms during the COVID19 pandemic than non-HCWs [16-18]. However, no study has yet investigated the longterm physical and mental rehabilitation of HCWs and its relationship with lung function. Therefore, we aimed to evaluate the long-term pulmonary, physical, and mental health rehabilitation of HCWs and their risk factors and correlation.

\section{METHODS}

\section{Study Design and Participants}

After COVID-19 was under control in China, the Chinese Academy of Engineering and Tencent Charity Foundation initiated a health care scheme named "Rehabilitation Care Project for Medical Staff Infected with COVID-19" for HCWs with COVID-19 after hospital discharge.
To date, the project has carried out follow-up studies up to 1 year after discharge. The assessed variables include: organ impairment, persistent symptoms, psychological problems, physical examinations, and consultation with academicians [19]. In this study, HCWs with mild or severe COVID-19 in Wuhan, China, who were discharged from the hospital 1 year prior to this study were invited to participate. They were selected among the participants of the "Rehabilitation Care Project for Medical Staff Infected with COVID-19" in China. Participants meeting the following criteria were excluded: (1) having a history of chronic lung disease, including asthma or chronic obstructive pulmonary disease (COPD), (2) having a history of psychiatric disorders, (3) being SARS-CoV-2 nucleic acid repositive, and (4) refusing to participate. The diagnosis of severe or mild COVID-19 pneumonia was based on the guidelines of the National Health Commission. This study was approved by the Ethics Committee of Union Hospital, Tongji Medical College, Huazhong University of Science and Technology (20200506), and was performed in accordance with the principles of the Declaration of Helsinki. Informed written consent was obtained from every study participant.

\section{Procedures}

The appointment for the follow-up visit was set by trained medical staff via telephone calls. All participants were contacted according to the discharge dates in their medical records. Followup consultations were performed in the outpatient clinic of the Wuhan Union Hospital. From 18 March to 30 April 2021, 525 HCWs who had recovered from COVID-19 were included in the "Rehabilitation Care Project for Medical Staff Infected with COVID-19" project. A total of 217/525 HCWs refused to undergo a lung function test, 5 had chronic lung diseases, and 303 underwent the lung function test and 6-min walk test (see the flowchart in Fig. 1). They also completed the St George's Respiratory Questionnaire (SGRQ), Essen Trauma Inventory (ETI), Dyspnea Assessment Questionnaire, and chest computed tomography (CT). SARS- 


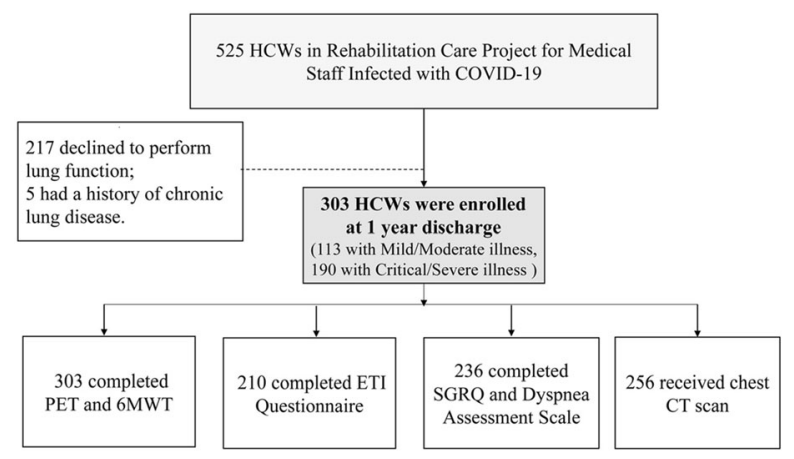

Fig. 1 Flowchart of participant recruitment. PFTs pulmonary function tests, $6 M W T$ 6-min walk test, $S G R Q$ St. George's Respiratory Questionnaire

COV-2 nucleic acid, antibody tests, immuneinflammation index, biochemical tests (liver and renal function, fasting plasma glucose, glycosylated hemoglobin, and myocardial injury markers), and coagulation tests were also completed simultaneously. Details of the lung function test and artificial intelligence-based quantitative analysis of CT images were presented in our previous study [20].

\section{Six-Minute Walk Test (6MWT)}

The 6-min walk test was performed according to a standardized protocol [21]. Oxygen saturation and heart rate were recorded before the start and at the end of the 6MWT. The percent predicted value for the $6 \mathrm{MWD}$ and the normative reference data were calculated using reference equations.

\section{Physical and Psychiatric Function Measurement}

The SGRQ is a standardized, self-administered, pulmonary-specific health status questionnaire containing 50 items and 76 weighted responses that are divided into three subscales: (1) symptoms (8 items), (2) activity (16 items), and (3) impacts (26 items). For each subscale and for the overall questionnaire, scores ranged from 0 to 100 and were calculated using score calculation algorithms. The normal values referred to the mean scores obtained from a sample of persons $(n=74)$ between 17 and 80 years old with no history of respiratory disease (mean forced expiratory volume in the first second $\left[\mathrm{FEV}_{1}\right], 95 \%$ ) (PW Jones, MD; Scoring Manual of the SGRQ May 2003) [22].

The Modified Medical Research Council (mMRC) dyspnea scale is used to assess dyspnea in many respiratory diseases [23]. Individuals are asked to choose the expression that best describes their level of dyspnea. The mMRC score ranges from 0 (no dyspnea) to 4 (perception of dyspnea during basic activities of daily life such as dressing) points.

The Borg scale is a valuable non-invasive test for the prediction of muscle weakness in patients [24]. Participants were first asked to score how dyspneic they felt using the Borg scale, which ranges from 0 (no dyspnea or fatigue at all) to 10 (excessive dyspnea or fatigue).

The ETI is a self-rating questionnaire that contains a list of 15 potentially traumatic events (personally experienced or witnessed) and items concerning the objective and subjective threat of life and symptoms on intrusion, hyperarousal, avoidance, and dissociation subscales [25]. Clinically relevant symptomatology according to the Diagnostic and Statistical Manual of Mental Disorders-IV (DSM-IV) is indicated by the presence of one traumatic event, objective and subjective threat to life, and achieving a cut-off $\geq 27$ points for the total sum score of the intrusion, hyperarousal, and avoidance subscales [26].

\section{Statistical Analysis}

All data analyses were performed using SPSS statistical software (version 20.0; IBM Corp). The significance level was set at $\alpha=0.05$, and all tests were two-tailed [2]. Categorical variables are presented as counts (\%), and continuous variables are expressed as medians (interquartile range [IQR]) [20]. To compare the differences in clinical characteristics, laboratory findings, pulmonary function, CT abnormalities, and physical and psychiatric function among surviving HCWs with different disease severities, we used the Kruskal-Wallis test or Wilcoxon signed-rank test for continuous variables and the chi-squared test or Fisher's exact test for 
categorical variables. Associations between pulmonary function results and CT quantitative data, and physical and psychiatric function scores, were examined using Spearman correlation analysis and visualized with corresponding correlation matrix plots [20]. To determine potential risk factors for diffusion impairment, probable post-traumatic stress disorder (PTSD), and physical function impairment, a multivariable logistic regression analysis was performed. The associations between risk factors and outcomes are presented as odds ratios (ORs) and 95\% confidence intervals (CIs) [2].

\section{RESULTS}

\section{Clinical Characteristics of the Study Population}

A total of 303 surviving HCWs were enrolled in this study. The demographic and clinical characteristics of the participants are presented in Table 1 . The median age of the enrolled participants was 39.0 (33.0-48.0) years, with 59 (19.47\%) men and 244 (80.53\%) women. Furthermore, 98 (32.34\%) were medical doctors, $162(53.47 \%)$ were nurses, and 43 (14.19\%) were health care assistants. The median length of hospital stay was 15.00 (9.00-26.00) days. The median time from discharge to follow-up visit was 395.00 (382.00-408.00) days. Of the participants, $96.7 \%$ had no smoking history. The most common comorbidity was hypertension (15 patients, $4.95 \%)$, followed by hyperlipidemia (4 patients, $1.32 \%$ ) and heart, endocrine, and liver diseases (2 patients, 1.32\%). COVID-19 was classified as mild/moderate in 113 (37.3\%) participants and as critical/severe in 190 (62.7\%) patients. Compared with participants with mild/moderate illness, participants with critical/severe illness were older $(39.00$ [34.00-49.00] vs. 38.00 [31.00-46.00] years) and higher body mass index (BMI); however, there was no significant difference in sex and comorbidities between the two COVID-19 severity groups. Of the 303 participants, 196 (64.69\%) required oxygen therapy during their hospital stay. One year after discharge, 83.45\% of the recovered HCWs still had positive serum
SARS-CoV-2 IgG tests, and the rate was significantly higher among HCWs who survived critical/severe $(89.27 \%)$ illness than among those with mild/moderate illness $(73.83 \%)$. The rate of positive serum SARS-CoV-2 IgM tests was higher in HCWs who survived critical/severe illness than in HCWs who survived mild/moderate illness $(16.38 \%$ vs. 9.35\%, $p=0.0949)$. Results of blood biochemistry, immune-inflammation index, glucose, glycosylated hemoglobin, myocardial injury markers, and coagulation function tests are shown in Supplemental Table 1. All the indicators returned to normal levels and were comparable between the critical/severe illness and mild/moderate groups.

\section{Pulmonary Function and 6MWT of Surviving HCWs 1 Year After Discharge}

Details of the lung function of surviving HCWs 1 year after hospital discharge are presented in Table 2. Only few surviving HCWs had ventilation defects or impaired lung volume. $\mathrm{FEV}_{1} \%$, forced vital capacity (FVC)\%, $\mathrm{FEV}_{1} / \mathrm{FVC}$, total lung capacity (TLC)\%, residual volume $(\mathrm{RV}) \%$, and small airway function were not within normal ranges in 23 (7.59\%), 7 (2.31\%), $24(7.92 \%), 16(5.28 \%), 8(2.64 \%)$, and 14 (2.31\%) HCWs, respectively. However, anomalies of diffusion capacity were common: $47.67 \%$ of the mild/moderate illness group and $40.97 \%$ in the critical/severe illness group had a reduced carbon monoxide diffusing capacity (DLCO)\%. However, there was no significant difference in lung function rehabilitation between the two groups. Comparing the pulmonary function of patients who required oxygen therapy during hospitalization with those who did not, there was no significant difference in $\mathrm{FVC} \%, \mathrm{FEV}_{1} \%$, $\mathrm{FEV}_{1} / \mathrm{FVC}$ ratio, or DLCO $\%$ between the two groups. Patients who received mechanical oxygen therapy had significantly lower RV/TLC values than those who did not (Supplemental Table 2). Of the 303 participants, 99 underwent a lung function test at 6 months after discharge. As shown in Supplemental Table 3, there were no significant differences in $\mathrm{FVC} \%, \mathrm{FEV}_{1} \%$, FEV1/FVC, TLC\%, RV\%, and RV/TLC between 6 
Table 1 Characteristics of enrolled surviving HCWs

\begin{tabular}{|c|c|c|c|c|}
\hline \multirow[t]{2}{*}{ Characteristics } & \multirow[t]{2}{*}{ All } & \multicolumn{3}{|l|}{ Group $(N=303)$} \\
\hline & & $\begin{array}{l}\text { HCWs with } \mathrm{mild} / \text { moderate } \\
\text { illness }(n=113)\end{array}$ & $\begin{array}{l}\text { HCWs with critical/severe } \\
\text { illness }(n=190)\end{array}$ & $p$ value \\
\hline $\begin{array}{l}\text { Age, median (IQR), } \\
\text { years }\end{array}$ & $39.00(33.00-48.00)$ & $38.00(31.00-46.00)$ & $39.00(34.00-49.00)$ & 0.0476 \\
\hline \multicolumn{5}{|l|}{ Sex } \\
\hline Female, $n(\%)$ & $244(80.53)$ & $91(80.53)$ & $153(80.53)$ & 0.9992 \\
\hline $\begin{array}{l}\text { BMI, median (IQR), } \\
\mathrm{kg} / \mathrm{m}^{2}\end{array}$ & $23.44(21.30-25.71)$ & $22.72(20.96-24.99)$ & $24.00(21.48-25.97)$ & 0.0093 \\
\hline \multicolumn{5}{|l|}{ Cigarette smoking } \\
\hline Never smoked, $n(\%)$ & $293(96.7)$ & $112(99.1)$ & $181(95.3)$ & 0.068 \\
\hline \multicolumn{5}{|l|}{ Comorbidities } \\
\hline Hypertension & $15(4.95)$ & $3(2.65)$ & $12(6.32)$ & 0.1554 \\
\hline Hyperlipidemia & $4(1.32)$ & $2(1.77)$ & $2(1.05)$ & 0.5968 \\
\hline Diabetes & $2(0.66)$ & $1(0.88)$ & $1(0.53)$ & 1.0000 \\
\hline Heart disease & $4(1.32)$ & $1(0.88)$ & $3(1.58)$ & 0.6088 \\
\hline Endocrine disease & $4(1.32)$ & $1(0.88)$ & $3(1.58)$ & 0.6088 \\
\hline Liver disease & $4(1.32)$ & $3(2.65)$ & $1(0.53)$ & 0.1165 \\
\hline Solid tumor & $2(0.66)$ & $1(0.88)$ & $1(0.53)$ & 1.0000 \\
\hline \multicolumn{5}{|l|}{ Occupation } \\
\hline Doctor & $98(32.34)$ & $39(34.51)$ & $59(31.05)$ & 0.9992 \\
\hline Nurse & $162(53.47)$ & $56(49.56)$ & $106(55.79)$ & \\
\hline Health care assistants & $43(14.19)$ & $18(15.93)$ & $25(13.16)$ & \\
\hline \multicolumn{5}{|c|}{ Oxygen supply during hospital stay } \\
\hline $\begin{array}{l}\text { Not requiring } \\
\text { supplemental oxygen }\end{array}$ & $102(33.66)$ & $54(47.79)$ & $48(25.26)$ & 0.0001 \\
\hline Nasal cannula or mask & $196(64.69)$ & $59(52.21)$ & $137(72.11)$ & 0.0005 \\
\hline $\begin{array}{l}\text { Time from discharge to } \\
\text { follow-up, days }\end{array}$ & $395.00(382.00-408.00)$ & $390.00(380.00-405.00)$ & $398.00(383.00-410.00)$ & 0.0646 \\
\hline $\begin{array}{l}\text { Length of hospital stay, } \\
\text { days }\end{array}$ & $15.00(9.00-26.00)$ & $13.00(5.00-23.00)$ & $17.50(11.00-27.00)$ & 0.0101 \\
\hline \multicolumn{5}{|l|}{ Serum antibody } \\
\hline IgM positive, $n(\%)$ & $39(13.73)$ & $10(9.35)$ & $29(16.38)$ & 0.0949 \\
\hline
\end{tabular}


Table 1 continued

\begin{tabular}{|c|c|c|c|c|}
\hline \multirow[t]{2}{*}{ Characteristics } & \multirow[t]{2}{*}{ All } & \multicolumn{3}{|l|}{ Group $(N=303)$} \\
\hline & & $\begin{array}{l}\text { HCWs with mild/moderate } \\
\text { illness }(n=113)\end{array}$ & $\begin{array}{l}\text { HCWs with critical/severe } \\
\text { illness }(n=190)\end{array}$ & $p$ value \\
\hline IgG positive, $n(\%)$ & $237(83.45)$ & 79 (73.83) & $158(89.27)$ & 0.0007 \\
\hline
\end{tabular}

Data are presented as median (interquartile range, IQR) for continuous variables and $n$ (\%) for categorical variables. Kruskal-Wallis (K-W) test was used for continuous variables and chi-square test or Fisher's exact test for all categorical variables

$H C W s$ health care workers, $I Q R$ interquartile range, $B M I$ body mass index

and 12 months of follow-up. However, the DLCO $\%$ and DLCO/alveolar volume\% improved significantly from 82.3 to $85.5 \%$ and from 86.8 to $91.6 \%$ at 12 months, respectively. To determine whether surviving HCWs with reduced lung function at 6 months improved by 1 year, we compared the FEV1/FVC, TLC\%, DLCO $\%$, and DLCO/VA\% at these two time points. There was a slight increase in DLCO\% $(4.1, p<0.0001)$ and DLCO/VA\% $(2.4, p<0.01)$ (Fig. 2).

Compared with participants with mild/moderate illness, participants with criti$\mathrm{cal} /$ severe illness presented with a shorter walking distance in meters in $6 \mathrm{~min}$ (549.50, IQR 514.0-582.0 vs. 564.0, 525.0-603.0). The proportion of patients with a median 6-min walking distance below the lower limits of normal (LLN) was $19.4 \%(58 / 303)$, and there was no significant difference between the two groups. None of the patients experienced significant hypoxia after the $6 \mathrm{MWT}$.

\section{Residual CT Abnormalities of Surviving HCWs 1 Year After Discharge and Their Correlation with Lung Function}

High-resolution CT was performed for 256 participants (Table 3). Chest CT revealed that $37.5 \%(96 / 256)$ of the HCWs still had abnormal CT findings, but there was no significant difference between the groups. Regarding lesion characteristics, ground-glass opacity (GGO), which is the most common CT finding in patients with COVID-19 in the acute phase, remained the most common 1 year after discharge $(24.6 \%)$. GGO was followed by fibroticlike changes $(10.2 \%)$ and thickening of the adjacent pleura (8.6\%) [27]. Artificial intelligence (AI)-derived CT features for quantifying pneumonia lesions were further studied to assess lung rehabilitation. Bilateral consolidation and GGO were absorbed approximately 12 months after discharge. Two cases with serial CT scans are shown in Fig. 3A, and the AI-based segmentation of lesions is shown in Fig. 3B. The associations between residual CT abnormalities and lung function parameters are shown in Fig. 4A: there was a significant negative correlation between the scope of residual CT abnormalities and obstructive ventilatory function parameters (such as $\mathrm{FEV}_{1} \%$, maximal expiratory flow at $50 \%$ of the forced vital capacity [MEF50], and MEF75/50), although the correlation was weak $(r<0.2, p<0.05)$. There was a weak correlation between DLCO $\%$ and bilateral residual GGO $(r<0.2, p<0.05)$.

\section{Physical and Psychiatric Function of Surviving HCWs 1 Year After Discharge and the Correlation with Lung Function}

One year after the HCWs were discharged from the hospital, physical function was measured using SGRQ, mMRC, and Borg scores (Table 4). The median SGRQ total score was 70.75 (27.44-106.57), which was higher than that of the healthy controls. In relation to the SGRQ 
Table 2 Pulmonary function and 6MWT of surviving HCWs

\begin{tabular}{|c|c|c|c|c|}
\hline \multirow[t]{2}{*}{ Characteristics } & \multirow[t]{2}{*}{ All } & \multicolumn{3}{|l|}{ Group $(n=303)$} \\
\hline & & $\begin{array}{l}\text { HCWs with } \\
\text { mild/moderate illness } \\
(n=113)\end{array}$ & $\begin{array}{l}\text { HCWs with } \\
\text { critical/severe illness } \\
(n=190)\end{array}$ & $p$ value \\
\hline $\begin{array}{l}\text { Age, median (IQR), } \\
\text { years }\end{array}$ & $39.00(33.00-48.00)$ & $38.00(31.00-46.00)$ & $39.00(34.00-49.00)$ & 0.0476 \\
\hline \multicolumn{5}{|l|}{ Sex } \\
\hline Female, $n(\%)$ & $244(80.53)$ & $91(80.53)$ & $153(80.53)$ & 0.9992 \\
\hline $\begin{array}{l}\text { BMI, median (IQR), } \\
\mathrm{kg} / \mathrm{m}^{2}\end{array}$ & $23.44(21.30-25.71)$ & $22.72(20.96-24.99)$ & $24.00(21.48-25.97)$ & 0.0093 \\
\hline \multicolumn{5}{|l|}{ Spirometry, median (IQR) } \\
\hline FEV1 (l), \% predicted & $98.00(89.80-106.00)$ & $97.90(90.20-105.30)$ & $98.00(89.60-106.00)$ & 0.9099 \\
\hline$<80 \%$ pred, $n / N(\%)$ & $23(7.59)$ & $11(9.73)$ & $12(6.32)$ & 0.2772 \\
\hline $\begin{array}{l}\text { VCmax (l), \% } \\
\text { predicted }\end{array}$ & $104.90(97.70-112.80)$ & $105.10(96.20-111.40)$ & $104.90(97.90-113.60)$ & 0.4297 \\
\hline FVC (l), \% predicted & $106.70(99.00-115.40)$ & $106.50(97.90-114.40)$ & $107.05(99.40-115.70)$ & 0.2603 \\
\hline$<80 \%$ pred, $n / N(\%)$ & $7(2.31)$ & $4(3.54)$ & $3(1.58)$ & 0.2719 \\
\hline FEV1/FVC, \% & $77.90(74.46-81.69)$ & $78.73(74.30-81.89)$ & $77.53(74.56-81.43)$ & 0.191 \\
\hline$<70 \%, n / N(\%)$ & $24(7.92)$ & $9(7.96)$ & $15(7.89)$ & 0.9826 \\
\hline FEV1/VCmax, \% & $77.58(74.03-81.33)$ & $77.97(74.30-81.57)$ & $77.06(73.88-80.89)$ & 0.1456 \\
\hline $\operatorname{PEF}(1 / s), \%$ predicted & $104.90(95.10-114.50)$ & $104.30(93.80-110.20)$ & $105.60(95.70-116.10)$ & 0.0252 \\
\hline $\begin{array}{l}\text { MEF75 (1/s), \% } \\
\text { predicted }\end{array}$ & $99.60(85.70-113.50)$ & $98.70(84.10-110.80)$ & $100.55(86.00-113.70)$ & 0.4874 \\
\hline$<65 \%$ pred, $n / N(\%)$ & $14(4.62)$ & $3(2.65)$ & $11(5.79)$ & 0.2088 \\
\hline $\begin{array}{l}\text { MEF50 (l/s), \% } \\
\text { predicted }\end{array}$ & $71.90(59.90-86.50)$ & $70.90(60.60-86.50)$ & $72.25(59.00-86.00)$ & 0.8654 \\
\hline$<65 \%$ pred, $n / N(\%)$ & $113(37.29)$ & $44(38.94)$ & $69(36.32)$ & 0.6481 \\
\hline $\begin{array}{l}\text { MEF25 (l/s), \% } \\
\text { predicted }\end{array}$ & $49.40(38.20-62.20)$ & $53.70(40.40-63.00)$ & $47.80(37.30-61.80)$ & 0.0887 \\
\hline \multicolumn{5}{|c|}{ Lung volume, median (IQR) } \\
\hline TLC (l) \% predicted & $96.70(91.00-103.10)$ & $97.10(91.10-103.20)$ & $96.65(90.90-102.90)$ & 0.8388 \\
\hline$<80 \%$ pred, $n / N(\%)$ & $16(5.28)$ & $6(5.31)$ & $10(5.26)$ & 0.986 \\
\hline RV (l) \% predicted & $95.50(84.60-105.60)$ & $98.30(86.30-108.70)$ & $93.65(83.90-103.20)$ & 0.0632 \\
\hline$<65 \%$ pred, $n / N(\%)$ & $8(2.64)$ & $3(2.65)$ & $5(2.63)$ & 0.9902 \\
\hline FRC (l) \% predicted & $95.15(83.30-110.40)$ & $102.60(86.90-112.40)$ & $93.00(82.50-107.10)$ & 0.005 \\
\hline RV/TLC, \% & $31.34(27.90-34.57)$ & $31.61(27.37-34.99)$ & $31.26(27.92-34.48)$ & 0.8009 \\
\hline
\end{tabular}


Table 2 continued

\begin{tabular}{|c|c|c|c|c|}
\hline \multirow[t]{2}{*}{ Characteristics } & \multirow[t]{2}{*}{ All } & \multicolumn{3}{|l|}{ Group $(n=303)$} \\
\hline & & $\begin{array}{l}\text { HCWs with } \\
\text { mild/moderate illness } \\
(n=113)\end{array}$ & $\begin{array}{l}\text { HCWs with } \\
\text { critical/severe illness } \\
(n=190)\end{array}$ & $p$ value \\
\hline FRC/TLC, \% & $53.73(47.96-59.48)$ & $55.42(49.91-62.09)$ & $52.58(47.19-58.19)$ & 0.0007 \\
\hline \multicolumn{5}{|c|}{ Diffusion capacity $(n=200)$, median (IQR) } \\
\hline $\begin{array}{l}\mathrm{DLCO}, \mathrm{mmol} / \mathrm{min} / \\
\mathrm{kPa}\end{array}$ & $7.16(6.39-8.42)$ & $7.05(6.34-8.35)$ & $7.20(6.43-8.43)$ & 0.8478 \\
\hline DLCO $\%$ predicted & $84.60(76.90-95.00)$ & $84.20(76.30-94.60)$ & $84.80(77.60-95.10)$ & 0.5984 \\
\hline$<80 \%$ pred, $n / N(\%)$ & $100(43.48)$ & $41(47.67)$ & $59(40.97)$ & 0.3212 \\
\hline $\begin{array}{l}\mathrm{DLCO} / \mathrm{VA}, \mathrm{mmol} / \\
\mathrm{min} / \mathrm{kPa} / \mathrm{l}\end{array}$ & $1.571 .42-1.73)$ & $1.53(1.42-1.71)$ & $1.58(1.42-1.75)$ & 0.9874 \\
\hline $\begin{array}{l}\mathrm{DLCO} / \mathrm{VA} \% \\
\text { predicted }\end{array}$ & $91.40(81.50-100.40)$ & $90.70(81.00-98.10)$ & $91.80(81.70-101.00)$ & 0.3789 \\
\hline$<80 \%$ pred, $n / N(\%)$ & $58(29.15)$ & $23(30.67)$ & $35(28.23)$ & 0.7135 \\
\hline $\begin{array}{l}\text { Distance walked in } \\
6 \text { min, median } \\
\text { (IQR), m }\end{array}$ & $555.00(516.00-591.00)$ & $564.00(525.00-603.00)$ & $549.50(514.00-582.00)$ & 0.0435 \\
\hline $\begin{array}{l}\text { Percentage of } \\
\text { predicted value, \% }\end{array}$ & $87.00(81.00-94.00)$ & $86.00(81.00-94.00)$ & $87.00(81.00-94.00)$ & 0.8173 \\
\hline $\begin{array}{l}\text { Less than lower limit } \\
\text { of the normal range }\end{array}$ & $58(19.4)$ & $23(20.4)$ & $35(18.8)$ & 0.8610 \\
\hline
\end{tabular}

Data are presented as median (interquartile range, IQR) for continuous variables and $n$ (\%) for categorical variables. Kruskal-Wallis $(\mathrm{K}-\mathrm{W})$ test was used for continuous variables and chi-square test or Fisher's exact test for all categorical variables. DLCO was measured through single-breath method

$H C W s$ health care workers, $I Q R$ interquartile range, $B M I$ body mass index, $F E V I$ forced expiratory volume in $1 \mathrm{~s}, V C$ vital capacity, $F V C$ forced vital capacity, $P E F$ peak expiratory flow, $M E F$ maximal expiratory flow, $T L C$ total lung capacity, $R V$ residual volume, $F R C$ functional residual capacity, $S B$ single-breath method, $D L C O$ diffusing capacity of the lung for carbon monoxide, $V A$ alveolar ventilation

subscale scores, the symptoms score was 17.25 (6.32-34.83), the activity score was 35.24 (11.94-47.69), and impacts score was 13.65 (3.83-32.31). The SGRQ total score and three sub-aspect scores were all significantly higher in the critical/severe illness group than in the mild/moderate illness group. A total of 143 (60.59\%) surviving HCWs had mMRC grade $\geq 1$ dyspnea. After exercise, $85.59 \%$ of the HCWs had dyspnea or Borg scale score $>1$. The rate of mMRC and Borg scores $>1$ was significantly higher in participants with critical/severe illness. The validated Chinese version of the ETI was used to diagnose probable PTSD (Table 5). The 1-year prevalence of probable PTSD (sum of the intrusion, avoidance, and hyperarousal 

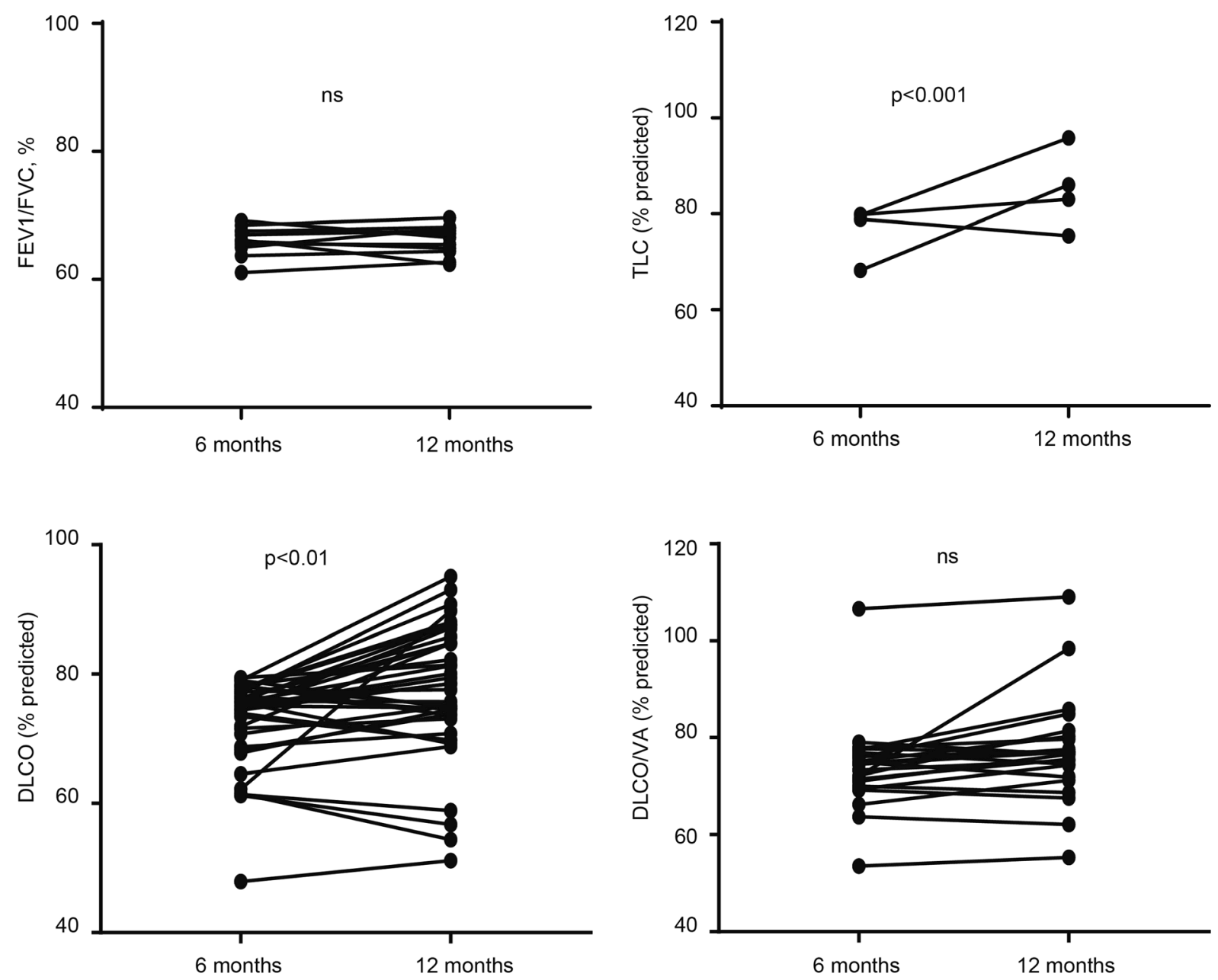

Fig. 2 TLC, \% predicted, FEV1/FVC, \%, DLCO, \% predicted, and DLCO/VA\% predicted at 6 and 12 months of followup in HCWs with isolated baseline decrease in lung function. ${ }^{*} p<0.05,{ }^{* * *} p<0.001 ;{ }^{* *} p<0.01$

scores $>27$ points) was $21.90 \%$; however, there was no significant difference between the two groups. There were no correlations of SGRQ, mMRC, and Borg scores with lung function parameters (Fig. 4B and C). However, there was a significant negative correlation between PTSD symptom scores and DLCO.

\section{Risk Factors for Diffusion Impairment, Probable PTSD, and Physical Function Impairment}

Twelve months after discharge, surviving HCWs presented with lung diffusion function impairment, physical function impairment, and PTSD.
A multiple linear regression analysis was performed to explore the association among diffusion function impairment, physical function impairment, PTSD, and sociodemographic variables (sex, age, and education). Women had an OR of 7.83 (95\% CI 2.54-24.13) for diffusion impairment. There was no significant association between other sociodemographic variables and impairment of diffusion function. Participants with critical/severe illness in the acute phase had an OR of 7.02 (95\% CI 2.44-11.61) for physical function impairment. Nurses had an OR of 6.22 (95\% CI 0.81-11.65) for physical function impairment. The risk of PTSD was not significant (Fig. 5). 
Table 3 Residual CT abnormities of surviving HCWs

\begin{tabular}{|c|c|c|c|c|}
\hline & \multirow[t]{2}{*}{ All } & \multicolumn{3}{|l|}{ Group $(n=256)$} \\
\hline & & $\begin{array}{l}\text { HCWs with } \\
\text { mild/moderate illness } \\
(n=98)\end{array}$ & $\begin{array}{l}\text { HCWs with } \\
\text { critical/severe illness } \\
(n=158)\end{array}$ & $p$ value \\
\hline $\begin{array}{l}\text { At least one abnormal CT pattern, } \\
n(\%)\end{array}$ & $96(37.5)$ & $33(33.7)$ & $63(39.9)$ & 0.319 \\
\hline GGO, $n(\%)$ & $63(24.6)$ & $20(20.4)$ & $43(27.2)$ & 0.219 \\
\hline Fibrotic-like changes, $n(\%)$ & $26(10.2)$ & $10(10.2)$ & $16(10.1)$ & 0.984 \\
\hline Consolidation, $n(\%)$ & $8(3.1)$ & $1(1)$ & $7(4.4)$ & 0.127 \\
\hline Parenchymal bands, $n$ (\%) & $9(3.5)$ & $4(4.1)$ & $5(3.2)$ & 0.699 \\
\hline Traction bronchiectasis, $n(\%)$ & $4(1.6)$ & $2(2.0)$ & $2(1.3)$ & 0.627 \\
\hline Lung architectural distortion, $n$ (\%) & $18(7.0)$ & $8(8.2)$ & $10(6.3)$ & 0.577 \\
\hline Reticulation, $n(\%)$ & $2(0.8)$ & $0(3.5)$ & $2(1.3)$ & 0.264 \\
\hline $\begin{array}{l}\text { Subpleural cystic airspace/BULLAE, } \\
n(\%)\end{array}$ & 0 & 0 & 0 & \\
\hline Thickening of adjacent pleura, $n(\%)$ & $22(8.6)$ & $9(9.2)$ & $13(8.2)$ & 0.791 \\
\hline $\begin{array}{l}\text { Volume of lung lesions, median } \\
\text { (IQR), } \mathrm{cm}^{3}\end{array}$ & $\begin{array}{l}0.03 \\
\quad(0.00-0.33)\end{array}$ & $0.01(0.00-0.43)$ & $0.05(0.00-0.29)$ & 0.125 \\
\hline $\begin{array}{l}\text { Volume of solid component, median } \\
\text { (IQR), } \mathrm{cm}^{3}\end{array}$ & $\begin{array}{l}0.01 \\
\quad(0.00-0.06)\end{array}$ & $0.00(0.00-0.05)$ & $0.01(0.00-0.07)$ & 0.382 \\
\hline Volume of GGO, median (IQR), $\mathrm{cm}^{3}$ & $\begin{array}{l}0.01 \\
\quad(0.00-0.23)\end{array}$ & $0.01(0.00-0.32)$ & $0.01(0.00-0.21)$ & 0.296 \\
\hline $\begin{array}{l}\text { Volume ratio of lung lesion to total } \\
\text { lung, median (IQR), \% }\end{array}$ & $\begin{array}{l}0.00 \\
\quad(0.00-0.01)\end{array}$ & $0.00(0.00-0.01)$ & $0.00(0.00-0.01)$ & 0.995 \\
\hline $\begin{array}{l}\text { Volume ratio of solid component to } \\
\text { total lung, median (IQR), \% }\end{array}$ & $\begin{array}{l}0.00 \\
\quad(0.00-0.00)\end{array}$ & $0.00(0.00-0.00)$ & $0.00(0.00-0.00)$ & 0.271 \\
\hline $\begin{array}{l}\text { Volume ratio of GGO to total lung, } \\
\text { median (IQR), \% }\end{array}$ & $\begin{array}{l}0.00 \\
\quad(0.00-0.01)\end{array}$ & $0.00(0.00-0.01)$ & $0.00(0.00-0.03)$ & 0.717 \\
\hline CT score, median (IQR), \% & $\begin{array}{l}0.00 \\
\quad(0.00-0.00)\end{array}$ & $0.00(0.00-0.00)$ & $0.00(0.00-0.00)$ & 0.917 \\
\hline
\end{tabular}

Data are presented as median (interquartile range, IQR) for continuous variables and $n$ (\%) for categorical variables. Kruskal-Wallis (K-W) test was used for continuous variables and chi-square test or Fisher's exact test for all categorical variables

$H C W s$ health care workers, $I Q R$ interquartile range, $G G O$ ground-glass opacity 
A
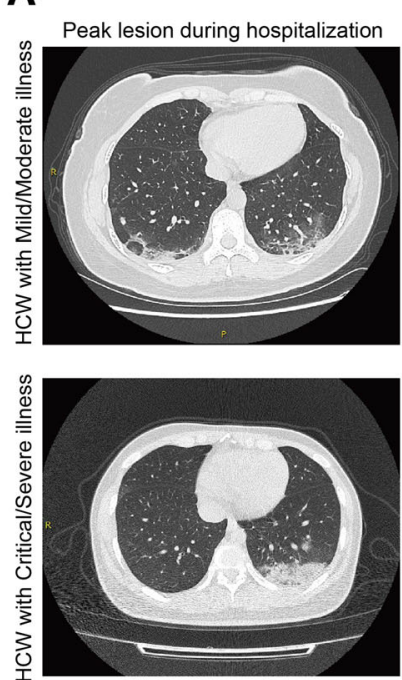

Fig. 3 Series CT scans of a representative moderate patient and a critical patient. A The upper row shows a 38-year-old woman with moderate COVID-19 pneumonia and the lower row a 37-year-old woman with critical COVID-19 pneumonia. The lesions of both patients on CT images dramatically decreased from discharge to

\section{DISCUSSION}

Some studies of the previous coronaviruses (Severe Acute Respiratory Syndrome and Middle East Respiratory Syndrome) reported long-term respiratory complications in some patients [28-30]. Despite few reports on the outcomes of HCWs during hospitalization, the long-term consequences of COVID-19 in HCWs who survive COVID-19 in the acute phase are uncertain [31-33]. In our study, we assessed lung function, residual CT abnormalities, and physical and psychiatric functions in surviving HCWs after the COVID-19 outbreak in China. One year after discharge, blood biochemistry test results, the immune-inflammation index, glycemia, glycosylated hemoglobin levels, myocardial injury, and coagulation function marker levels had returned to normal. Most surviving HCWs had positive IgG tests 1 year after discharge; this suggests that in survivors the risk of re-infection 1 year after discharge is low. However, decreased lung diffusion function, abnormal CT pattern, impaired physical
B

1 year after discharge
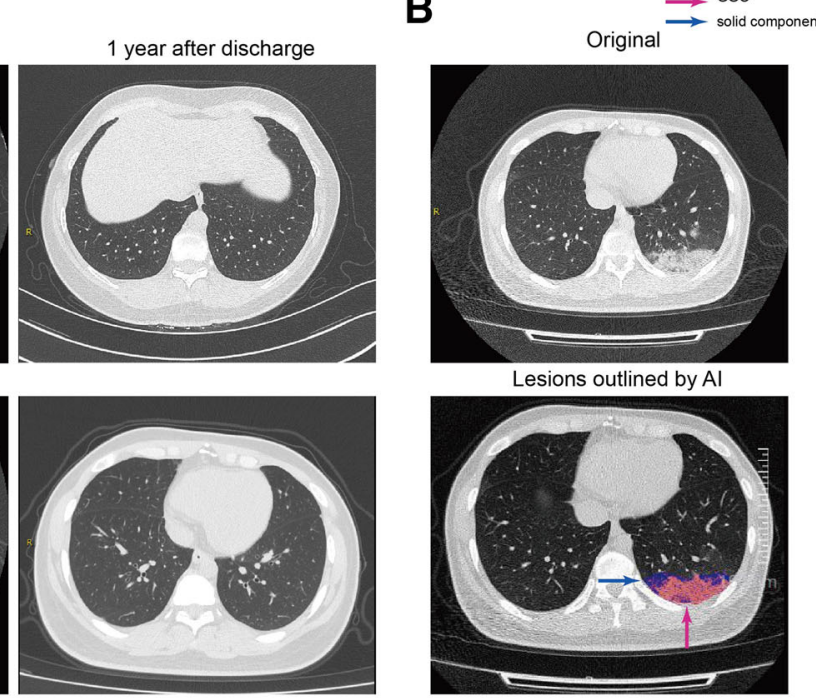

12-month follow-up. B Schematic diagram of lesions outlined by AI on CT images. The upper image is the original CT slice and the lower one the AI-based lesion outline. The outlined blue area represents lesions of GGO, and the red area represents lesions of the solid component

function, and psychiatric disorders were observed during the 1-year follow-up.

In this study, the lung function assessment showed that $40.97 \%$ of HCWs who survived mild/moderate COVID-19 and $47.67 \%$ of HCWs who survived severe/critical COVID-19 had a pulmonary diffusion abnormality 1 year after discharge. The diffusion capacity of the surviving HCWs was better at 1 year compared to that at 6 months. In our previous studies, we found that $41.7 \%$ of mild/moderate COVID-19 survivors and $47.1 \%$ of severe/critical COVID-19 survivors had a reduced DLCO at the 3-month follow-up [20]. A recent study reported that $78 / 243(32.1 \%)$ patients had a reduced DLCO 1 year after discharge [34]. Compared to the previous study (median age, 60.0 years), our study population was younger (median age 38.0 and 39.0 years in the mild/moderate and severe/critical groups, respectively), and our study had a larger sample size. Patients infected with SARS also had persistent lung function impairment: previous studies reported that $23.7 \%$ (85/ 311) of SARS survivors had impaired DLCO after 1 year [35]. The results suggest that the impact 
A

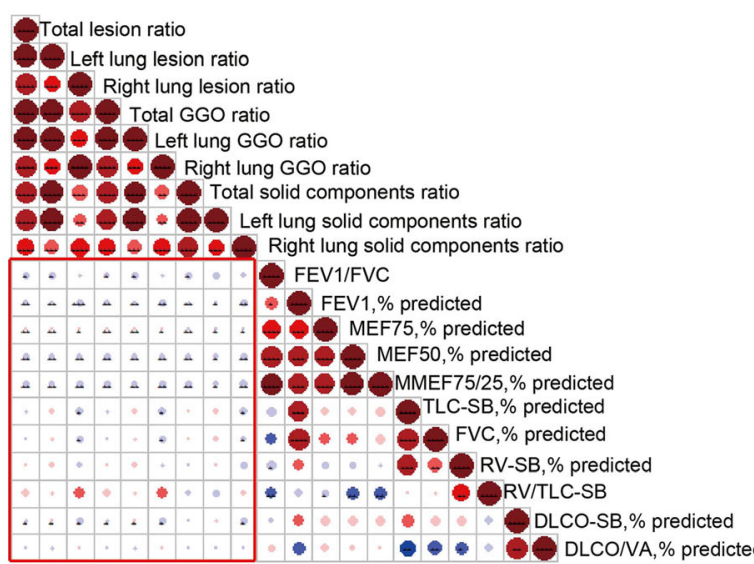

C

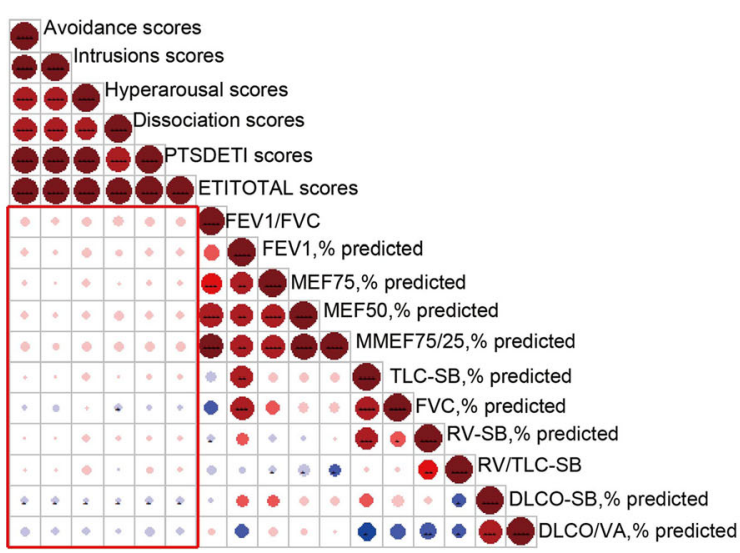

Fig. 4 Correlation analysis among pulmonary function, chest CT, physical function scores, and PTSD symptoms scores in surviving HCWs. A Correlation matrices of chest CT abnormalities and pulmonary function parameters at 12-month follow-up. B Correlation matrices of pulmonary function parameters and physical function scores at 12-month follow-up. C Correlation matrices of pulmonary

of SARS-CoV-2 on the pulmonary diffusion capacity is long-lasting; lung function recovery is slow in surviving HCWs, and the long-term lung function recovery of HCWs needs to be monitored. In the multivariable analysis in our study, surviving female HCWs had a higher risk of abnormal diffusion function; this is consistent with previous studies $[15,34,36]$. However, in our study, the proportion of nurses and females among infected HCWs was high. The underlying relationship between sex and impaired DLCO needs further investigation.

B

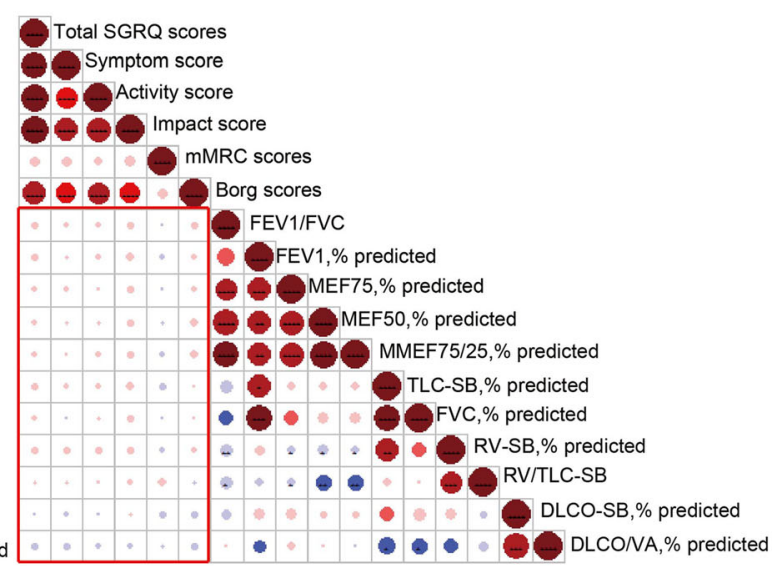

Scale: spearman Correlation coefficient ( $r$ )

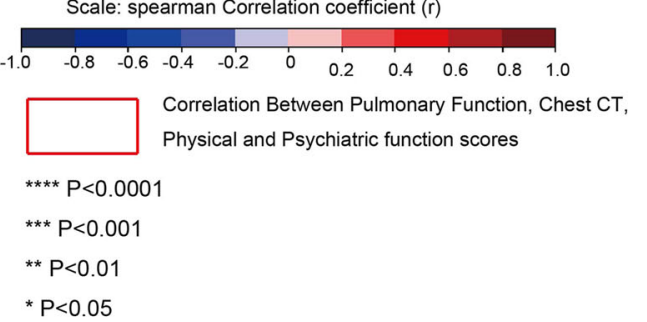

function parameters and PTSD symptoms scores at 12-month follow-up. The correlation analysis among the above three comparison groups is highlighted within the red rectangular boxes. Statistically significant correlations with $p<0.05$ have been marked as ${ }^{* * * *} p<0.0001$; ${ }^{* * *} p<0.001 ;{ }^{* *} p<0.01,{ }^{*} p<0.05$

The difference in lung function recovery was not significant between the mild/moderate and severe/critical COVID-19 groups. Furthermore, there was no association between disease severity and impairment of diffusion capacity in the multivariable analysis. However, pulmonary diffusion abnormality was associated with COVID-19 severity in the acute phase [15]. In this study, $19.4 \%$ of surviving HCWs had a reduced 6MWD; this proportion is higher than that in a study of COVID-19 survivors at 12 months post-discharge (12\%)[34]. By the end 
Table 4 Physical function of surviving HCWs

\begin{tabular}{|c|c|c|c|c|}
\hline \multirow{2}{*}{ Characteristics } & \multirow[t]{2}{*}{ All } & \multicolumn{3}{|l|}{ Group $(N=236)$} \\
\hline & & $\begin{array}{l}\text { HCWs with mild/moderate } \\
\text { illness }(n=88)\end{array}$ & $\begin{array}{l}\text { HCWs with critical/severe } \\
\text { illness }(n=148)\end{array}$ & $p$ value \\
\hline $\begin{array}{l}\text { Age, median } \\
\text { (IQR), years }\end{array}$ & $39.00(34.00-48.00)$ & $39.00(31.00-46.00)$ & $39.50(34.00-48.00)$ & 0.1845 \\
\hline \multicolumn{5}{|l|}{ Sex } \\
\hline Female, $n(\%)$ & $190(80.51)$ & $69(78.41)$ & $121(81.76)$ & 0.5301 \\
\hline $\begin{array}{l}\text { BMI, median } \\
\quad(\mathrm{IQR}), \mathrm{kg} / \mathrm{m}^{2}\end{array}$ & $23.60(21.32-25.78)$ & $22.83(20.97-25.19)$ & $24.00(21.48-25.95)$ & 0.0336 \\
\hline \multicolumn{5}{|l|}{ SGRQ, (IQR) } \\
\hline Symptoms scores & $17.25(6.32-34.83)$ & $15.49(5.12-32.42)$ & $21.7(6.96-37.32)$ & 0.022 \\
\hline Activity scores & $35.24(11.94-47.69)$ & $23.33(5.25-41.42)$ & $41.08(20.73-53.16)$ & 0.006 \\
\hline Impacts scores & $13.65(3.83-32.31)$ & $7.36(0-23.55)$ & $18.45(5.03-35.71)$ & 0.022 \\
\hline Total scores & $70.75(27.44-106.57)$ & $15.92(4.85-29.06)$ & $9.78(28.05-39.79)$ & 0.022 \\
\hline \multicolumn{5}{|l|}{ mMRC scores } \\
\hline 0 & $93(39.41)$ & $44(50.00)$ & $49(33.11)$ & 0.0102 \\
\hline$\geq 1$ & $143(60.59)$ & $44(50.00)$ & $99(66.89)$ & \\
\hline \multicolumn{5}{|l|}{ Borg scores } \\
\hline 0 & $34(14.41)$ & $18(20.45)$ & $16(10.81)$ & 0.0413 \\
\hline$\geq 1$ & $202(85.59)$ & $70(79.55)$ & $132(89.19)$ & \\
\hline
\end{tabular}

Data are presented as median (interquartile range, IQR) for continuous variables and $n$ (\%) for categorical variables. Kruskal-Wallis $(\mathrm{K}-\mathrm{W})$ test was used for continuous variables and chi-square test or Fisher's exact test for all categorical variables

$H C W s$ health care workers, $I Q R$ interquartile range, $B M I$ body mass index, $S G R Q$ St. George questionnaire, $m M R C$ scores modified Medical Research Council dyspnea scale

of the first year after discharge, 37.5\% (96/256) of surviving HCWs had an abnormal CT pattern, and this proportion was higher than the proportion in a prospective follow-up study of 41 COVID-19 survivors at 1 year (34.6\%) [37]. The most common abnormal CT pattern was pulmonary interstitial change (GGO, 24.6\%; fibrotic-like changes, $10.2 \%$ ), which was similar to the long-term lung manifestations of SARS [38]. This finding was consistent with the reported negative correlation of extent of CT abnormalities and DLCO.
Many of the data on physical and psychiatric issues, such as decreased health-related quality of life, dyspnea, sleep problems, PTSD, depression, and anxiety symptoms, have been reported in HCWs [13, 17, 35, 39]. Our study also investigated the physical and psychiatric functions of surviving HCWs. Most surviving HCWs had a physical decline 1 year after discharge, and the decline was worse in HCWs with severe disease than in those with moderate. Disease severity in the acute phase and in nurses was associated with a high risk of impaired physical function in the multivariable analysis; this 
Table 5 Scores of PTSD symptoms of HCWs

\begin{tabular}{|c|c|c|c|c|}
\hline \multirow[t]{2}{*}{ Characteristics } & \multirow[t]{2}{*}{ All } & \multicolumn{3}{|l|}{ Group $(N=210)$} \\
\hline & & $\begin{array}{l}\text { HCWs with mild/moderate } \\
\text { illness }(n=85)\end{array}$ & $\begin{array}{l}\text { HCWs with critical/severe } \\
\text { illness }(n=125)\end{array}$ & $p$ value \\
\hline $\begin{array}{l}\text { Age, median (IQR), } \\
\text { years }\end{array}$ & $\begin{array}{l}38.00 \\
\quad(33.00-48.00)\end{array}$ & $39.00(31.00-45.00)$ & $38.00(33.00-48.00)$ & 0.3764 \\
\hline \multicolumn{5}{|l|}{ Sex } \\
\hline Female, $n(\%)$ & $171(81.43)$ & $71(83.53)$ & $100(80.00)$ & 0.5186 \\
\hline $\begin{array}{l}\text { BMI, median (IQR), } \\
\mathrm{kg} / \mathrm{m}^{2}\end{array}$ & $\begin{array}{l}22.96 \\
\quad(21.23-25.47)\end{array}$ & $22.64(20.70-24.99)$ & $23.68(21.48-25.78)$ & 0.0404 \\
\hline \multicolumn{5}{|c|}{ PTSD symptoms scores, median (IQR) } \\
\hline Avoidance & $\begin{array}{l}7.00 \\
\quad(5.00-10.00)\end{array}$ & $7.00(4.00-9.00)$ & $8.00(5.00-10.00)$ & 0.0574 \\
\hline Intrusions & $\begin{array}{l}5.00 \\
\quad(4.00-7.00)\end{array}$ & $5.00(3.00-6.00)$ & $6.00(4.00-8.00)$ & 0.0484 \\
\hline Hyperarousal & $\begin{array}{l}6.00 \\
\quad(4.00-8.00)\end{array}$ & $6.00(4.00-8.00)$ & $6.00(4.00-8.00)$ & 0.1614 \\
\hline Dissociation & $\begin{array}{l}5.00 \\
\quad(2.00-7.00)\end{array}$ & $4.00(2.00-7.00)$ & $5.00(3.00-7.00)$ & 0.1084 \\
\hline PTSDETI scores & $\begin{array}{l}19.00 \\
\quad(13.00-26.00)\end{array}$ & $17.00(12.00-24.00)$ & $20.00(14.00-26.00)$ & 0.0542 \\
\hline $\begin{array}{l}\text { Possible PTSD, } \\
n(\%)\end{array}$ & $46(21.90)$ & $15(17.65)$ & $31(24.80)$ & \\
\hline
\end{tabular}

Data are presented as median (interquartile range, IQR) for continuous variables and $n$ (\%) for categorical variables. Kruskal-Wallis (K-W) test was used for continuous variables and chi-square test or Fisher's exact test for all categorical variables. DLCO was measured through single-breath method

$H C W s$ health care workers, $I Q R$ interquartile range, BMI body mass index, PTSD post-traumatic stress disorder

suggests that surviving $\mathrm{HCW}$ sad persistent physical function impairment, consistent with a previous follow-up survey of 538 patients with COVID-19 [40]. In a previous survey of first-line HCWs during the COVID-19 outbreak, HCWs in Wuhan reported more severe symptoms of depression, anxiety, insomnia, and distress than HCWs in Hubei (outside Wuhan) or outside Hubei [2]. An Italian study showed that the mental health state of HCWs was worsening during the emergency compared with the time before the SARS-CoV-2 pandemic onset, and female HCWs achieved higher depression symptom scores [39]. In our previous study, $19.9 \%$ of surviving HCWs had probable PTSD
6 months after acute exposure to COVID-19 [41]; by 1 year after discharge, the proportion was $21.90 \%$ in our study, and we found no statistical gender risk for PTSD. We also found that PTSD scores were negatively associated with DLCO, although the correlation was weak. Previous study reported that lifetime or 12-month experience of depression was associated with lower FEV1 and FEF25-75\%, but the PTSD do not predict a difference in respiratory function of young adults [42]. These results suggest that mental health care is an urgent need for surviving HCWs. To achieve this, various intervention methods are appropriate, such as training on stress management, reducing 


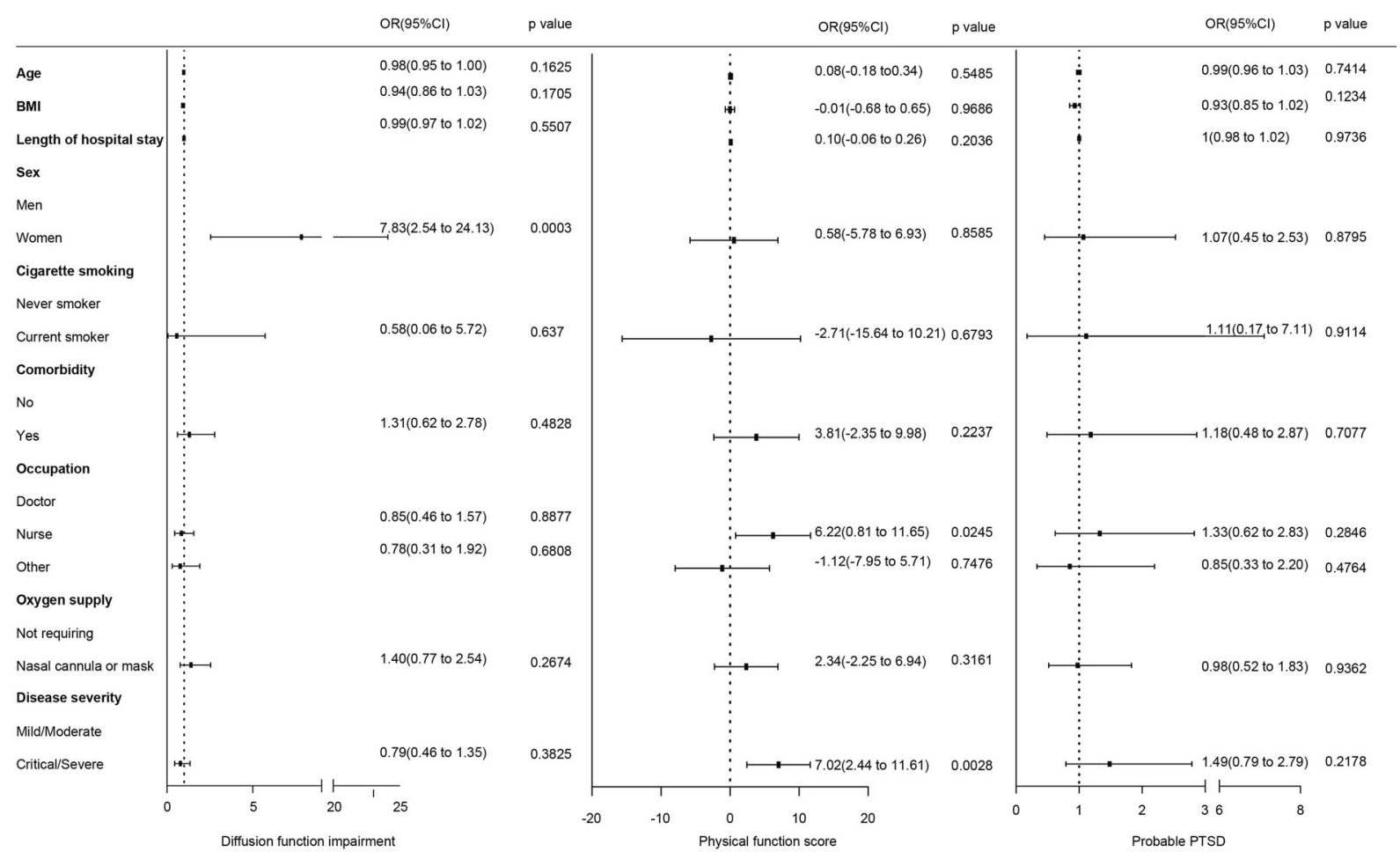

Fig. 5 Risk factors associated with diffusion impairment, physical function impairment, and possible PTSD. OR odds ratio

working hours, and providing psychological counseling.

This is the first study on long-term lung function, residual CT abnormalities, and physical and psychiatric functions in HCWs with COVID-19 after discharge. However, this study has several limitations. First, we lacked baseline data on pulmonary and physical function. However, the participants were young, and participants with chronic pulmonary disease were excluded. Furthermore, the observed impaired pulmonary function and physical function can be attributed in part to COVID-19. Second, we did not have the health rehabilitation data of non-HCWs matched according to age. The differences in health rehabilitation between HCWs and non-HCWs require further study. Third, individuals with COVID-19 consequences and who were more concerned about their health were more likely to participate in this study, which may have caused self-selection bias. This could have overestimated the probability of non-recovered surviving HCWs and exaggerated the impact of COVID-19.

\section{CONCLUSION}

Our results suggest that surviving HCWs experienced long-term consequences of COVID-19. These included pulmonary rehabilitation as well as physical and psychiatric function impairment. However, a comparison study of the difference in these long-term consequences between HCWs and non-HCWs is needed.

\section{ACKNOWLEDGEMENTS}

Funding. The Rehabilitation Care Project for Medical Staff Infected with COVID-19 was supported by the Chinese Academy of Engineering and Tencent Foundation, the National Natural Science Foundation of China (82041018, 82172034), and Wuhan Municipal Science and Technology Bureau for COVID-19 (2020020101010004). The Rapid Service Fees were funded by the authors. 
Medical Writing Assistance. Editorial assistance for this manuscript was provided by Editage, and the source of funding for this assistance was the authors.

Authorship. All named authors meet the International Committee of Medical Journal Editors (ICMJE) criteria for authorship for this article, take responsibility for the integrity of the work as a whole, and have given their approval for this version to be published.

Author Contributions. Tingting Liao, Daquan Meng, Lijuan Xiong, and Shuting Wu equally shared the workload: study design, data analysis and interpretation, and writing and revision. Lian Yang: data analysis and revision. Xinliang He, Xiongjing Cao, Huangguo Xiong and Yunzhou Fan: data collection. Sufei Wang: data collection and writing. Mei Zhou: revision. Jiahong Xia, $\mathrm{Yu} \mathrm{Hu}$ and Yang Jin contributed to the study concept, the study design, writing, and revision.

Disclosures. Tingting Liao, Daquan Meng, Lijuan Xiong, Shuting Wu, Lian Yang, Sufei Wang, Mei Zhou, Xinliang He, Xiongjing Cao, Huangguo Xiong, Yunzhou Fan, Jiahong Xia, $\mathrm{Yu} \mathrm{Hu}$, and Yang Jin all have nothing to disclose.

Compliance with Ethics Guidelines. This study was approved by the Ethics Committee of Union Hospital, Tongji Medical College, Huazhong University of Science and Technology (2020-0506), and was performed in accordance with the principles of the Declaration of Helsinki. Informed written consent was obtained from every study participant.

Data Availability. The datasets generated during and/or analyzed during the current study are available from the corresponding author on reasonable request.

Open Access. This article is licensed under a Creative Commons Attribution-NonCommercial 4.0 International License, which permits any non-commercial use, sharing, adaptation, distribution and reproduction in any medium or format, as long as you give appropriate credit to the original author(s) and the source, provide a link to the Creative Commons licence, and indicate if changes were made. The images or other third party material in this article are included in the article's Creative Commons licence, unless indicated otherwise in a credit line to the material. If material is not included in the article's Creative Commons licence and your intended use is not permitted by statutory regulation or exceeds the permitted use, you will need to obtain permission directly from the copyright holder. To view a copy of this licence, visit http://creativecommons.org/licenses/by$\mathrm{nc} / 4.0 /$.

\section{REFERENCES}

1. Zhu N, Zhang D, Wang W, Li X, Yang B, Song J, Zhao X, Huang B, Shi W, Lu R, et al. A novel coronavirus from patients with pneumonia in China, 2019. N Engl J Med. 2020;382(8):727-33.

2. Lai J, Ma S, Wang Y, Cai Z, Hu J, Wei N, Wu J, Du H, Chen T, Li R, et al. Factors associated with mental health outcomes among health care workers exposed to coronavirus disease 2019. JAMA Netw Open. 2020;3(3):e203976.

3. Rajkumar RP. COVID-19 and mental health: a review of the existing literature. Asian J Psychiatr. 2020;52:102066.

4. Nguyen LH, Drew DA, Graham MS, Joshi AD, Guo CG, Ma W, Mehta RS, Warner ET, Sikavi DR, Lo CH, et al. Risk of COVID-19 among front-line healthcare workers and the general community: a prospective cohort study. Lancet Public Health. 2020;5(9):e475-83.

5. Guan WJ, Ni ZY, Hu Y, Liang WH, Ou CQ, He JX, Liu L, Shan H, Lei CL, Hui DSC, et al. Clinical characteristics of coronavirus disease 2019 in China. N Engl J Med. 2020;382(18):1708-20.

6. Characteristics of Health Care Personnel with COVID-19-United States, February 12-April 9, 220. MMWR Morb Mortal Wkly Rep 2020;69(15): 477-481.

7. Krastinova E, Garrait V, Lecam MT, Coste A, Varon E, Delacroix I, Si Ali A, Jung C, Smati M, Cherbit M, et al. Household transmission and incidence of positive SARS-CoV-2 RT-PCR in symptomatic healthcare workers, clinical course and outcome: a 
French hospital experience. Occup Environ Med. 2020;78:479-85.

8. Chou R, Dana T, Buckley DI, Selph S, Fu R, Totten AM. Epidemiology of and risk factors for coronavirus infection in health care workers: a living rapid review. Ann Intern Med. 2020;173(2):120-36.

9. Ngai JC, Ko FW, Ng SS, To KW, Tong M, Hui DS. The long-term impact of severe acute respiratory syndrome on pulmonary function, exercise capacity and health status. Respirology. 2010;15(3): 543-50.

10. Ng CK, Chan JW, Kwan TL, To TS, Chan YH, Ng FY, Mok TY. Six month radiological and physiological outcomes in severe acute respiratory syndrome (SARS) survivors. Thorax. 2004;59(10):889-91.

11. Bonanno GA, Ho SM, Chan JC, Kwong RS, Cheung CK, Wong CP, Wong VC. Psychological resilience and dysfunction among hospitalized survivors of the SARS epidemic in Hong Kong: a latent class approach. Health Psychol. 2008;27(5):659-67.

12. Korompoki E, Gavriatopoulou M, Hicklen RS, Ntanasis-Stathopoulos I, Kastritis E, Fotiou D, Stamatelopoulos K, Terpos E, Kotanidou A, Hagberg $\mathrm{CA}$, et al. Epidemiology and organ specific sequelae of post-acute COVID19: a narrative review. J Infect. 2021;83(1):1-16.

13. Huang F, Yang Z, Wang Y, Zhang W, Lin Y, Zeng LC, Jiang X, Shang L. Health-related quality of life and influencing factors of pediatric medical staff during the COVID-19 outbreak. Front Public Health. 2020;8:565849.

14. Yang JY, Parkins MD, Canakis A, Aroniadis OC, Yadav D, Dixon RE, Elmunzer BJ, Forbes N. Outcomes of COVID-19 among hospitalized health care workers in North America. JAMA Netw Open. 2021;4(1):e2035699.

15. Huang C, Huang L, Wang Y, Li X, Ren L, Gu X, Kang L, Guo L, Liu M, Zhou X, et al. 6-month consequences of COVID-19 in patients discharged from hospital: a cohort study. Lancet. 2021;397(10270):220-32.

16. Moitra M, Rahman M, Collins PY, Gohar F, Weaver M, Kinuthia J, Rössler W, Petersen S, Unutzer J, Saxena S, et al. Mental health consequences for healthcare workers during the COVID-19 pandemic: a scoping review to draw lessons for LMICs. Front Psychiatry. 2021;12:602614.

17. Zhang WR, Wang K, Yin L, Zhao WF, Xue Q, Peng M, Min BQ, Tian Q, Leng HX, Du JL, et al. Mental health and psychosocial problems of medical health workers during the COVID-19 epidemic in China. Psychother Psychosom. 2020;89(4):242-50.
18. Wang W, Song W, Xia Z, He Y, Tang L, Hou J, Lei S. Sleep disturbance and psychological profiles of medical staff and non-medical staff during the early outbreak of COVID-19 in Hubei Province. China Front Psychiatry. 2020;11:733.

19. Xiong L, Li Q, Cao X, Xiong H, Huang M, Yang F, Liu Q, Meng D, Zhou M, Wang G, et al. Dynamic changes of functional fitness, antibodies to SARSCoV-2 and immunological indicators within 1 year after discharge in Chinese health care workers with severe COVID-19: a cohort study. BMC Med. 2021;19(1):163.

20. Zhou M, Xu J, Liao T, Yin Z, Yang F, Wang K, Wang Z, Yang D, Wang S, Peng Y, et al. Comparison of residual pulmonary abnormalities 3 months after discharge in patients who recovered from COVID19 of different severity. Front Med (Lausanne). 2021;8:682087.

21. Jay SJ. Reference equations for the six-minute walk in healthy adults. Am J Respir Crit Care Med. 2000;161(4 Pt 1):1396.

22. Ong KC, Ng AW, Lee LS, Kaw G, Kwek SK, Leow MK, Earnest A. 1-year pulmonary function and health status in survivors of severe acute respiratory syndrome. Chest. 2005;128(3):1393-400.

23. Casanova C, Marin JM, Martinez-Gonzalez C, de Lucas-Ramos P, Mir-Viladrich I, Cosio B, PecesBarba G, Solanes-García I, Agüero R, Feu-Collado N, et al. Differential effect of modified medical research council dyspnea, COPD assessment test, and clinical COPD questionnaire for symptoms evaluation within the new GOLD staging and mortality in COPD. Chest. 2015;148(1):159-68.

24. Just N, Bautin N, Danel-Brunaud V, Debroucker V, Matran R, Perez T. The Borg dyspnoea score: a relevant clinical marker of inspiratory muscle weakness in amyotrophic lateral sclerosis. Eur Respir J. 2010;35(2):353-60.

25. Tagay S, Düllmann S, Hermans E, Repic N, Hiller R, Senf W. The Essen Trauma-Inventory for children and adolescents (ETI-CA). Z Kinder Jugendpsychiatr Psychother. 2011;39(5):323-40.

26. Nacak Y, Morawa E, Erim Y. High rejection sensitivity in patients with somatoform pain disorder. Front Psychiatry. 2021;12:602981.

27. Han X, Fan Y, Alwalid O, Li N, Jia X, Yuan M, Li Y, Cao Y, Gu J, Wu H, et al. Six-month follow-up chest CT findings after severe COVID-19 pneumonia. Radiology. 2021;299(1):E177-e186.

28. Hui DS, Joynt GM, Wong KT, Gomersall CD, Li TS, Antonio G, Ko FW, Chan MC, Chan DP, Tong MW, et al. Impact of severe acute respiratory syndrome 
(SARS) on pulmonary function, functional capacity and quality of life in a cohort of survivors. Thorax. 2005;60(5):401-9.

29. Antonio GE, Wong KT, Hui DS, Wu A, Lee N, Yuen $\mathrm{EH}$, Leung CB, Rainer TH, Cameron P, Chung SS, et al. Thin-section CT in patients with severe acute respiratory syndrome following hospital discharge: preliminary experience. Radiology. 2003;228(3): 810-5.

30. Das KM, Lee EY, Singh R, Enani MA, Al Dossari K, Van Gorkom K, Larsson SG, Langer RD. Follow-up chest radiographic findings in patients with MERS$\mathrm{CoV}$ after recovery. Indian $\mathrm{J}$ Radiol Imaging. 2017;27(3):342-9.

31. Antonio-Villa NE, Bello-Chavolla OY, Vargas-Vazquez A, Fermin-Martinez CA, Marquez-Salinas A, Pisanty-Alatorre J, Bahena-Lopez JP. Assessing the burden of coronavirus disease 2019 (COVID-19) among healthcare workers in Mexico City: a datadriven call to action. Clin Infect Dis. 2021;73(1): e191-8.

32. Abohamr SI, Aldossari MA, Alaklobi FA, Amer HA, Alzarzour SH, Abdelhamid SW, Aljunaidi O, Badhawi OS, Siddiqui S, Jumaa $\mathrm{H}$, et al. Clinical characteristics and in-hospital outcome of medical staff infected with COVID-19 in Saudi Arabia. A retrospective single-center study. Saudi Med J. 2020;41(12):1336-43.

33. Yang JY, Parkins MD, Canakis A, Aroniadis OC, Yadav D, Dixon RE, Elmunzer BJ, Forbes N, Group DMCS, the North American Alliance for the Study of Digestive Manifestations of C. Outcomes of COVID-19 among hospitalized health care workers in North America. JAMA Netw Open. 2021;4(1): e2035699.

34. Huang L, Yao Q, Gu X, Wang Q, Ren L, Wang Y, Hu $\mathrm{P}$, Guo L, Liu $\mathrm{M}, \mathrm{Xu}$ J, et al. 1-year outcomes in hospital survivors with COVID-19: a longitudinal cohort study. Lancet. 2021;398(10302):747-58.

35. Hui DS, Wong KT, Ko FW, Tam LS, Chan DP, Woo J, Sung JJ. The 1-year impact of severe acute respiratory syndrome on pulmonary function, exercise capacity, and quality of life in a cohort of survivors. Chest. 2005;128(4):2247-61.

36. Wu X, Liu X, Zhou Y, Yu H, Li R, Zhan Q, Ni F, Fang S, Lu Y, Ding X, et al. 3-month, 6-month, 9-month, and 12-month respiratory outcomes in patients following COVID-19-related hospitalisation: a prospective study. Lancet Respir Med. 2021;9(7): 747-54.

37. Chen Y, Ding C, Yu L, Guo W, Feng X, Yu L, Su J, $\mathrm{Xu} \mathrm{T}$, Ren C, Shi D, et al. One-year follow-up of chest CT findings in patients after SARS-CoV-2 infection. BMC Med. 2021;19(1):191.

38. Zhang P, Li J, Liu H, Han N, Ju J, Kou Y, Chen L, Jiang M, Pan F, Zheng Y, et al. Long-term bone and lung consequences associated with hospital-acquired severe acute respiratory syndrome: a 15-year follow-up from a prospective cohort study. Bone Res. 2020;8:8.

39. Farì G, de Sire A, Giorgio V, Rizzo L, Bruni A, Bianchi FP, Zonno A, Pierucci P, Ranieri M, Megna M. Impact of COVID-19 on the mental health in a cohort of Italian rehabilitation healthcare workers. J Med Virol 2021.

40. Xiong Q, Xu M, Li J, Liu Y, Zhang J, Xu Y, Dong W. Clinical sequelae of COVID-19 survivors in Wuhan, China: a single-centre longitudinal study. Clin Microbiol Infect. 2021;27(1):89-95.

41. Xiong LJ, Zhong BL, Cao XJ, Xiong HG, Huang M, Ding J, Li WT, Tong J, Shen HY, Xia JH, et al. Possible posttraumatic stress disorder in Chinese frontline healthcare workers who survived COVID196 months after the COVID-19 outbreak: prevalence, correlates, and symptoms. Transl Psychiatry. 2021;11(1):374.

42. Hayatbakhsh MR, Najman JM, Clavarino A, Bor W, Williams GM, O'Callaghan MJ. Association of psychiatric disorders, asthma and lung function in early adulthood. J Asthma. 2010;47(7):786-91. 